\title{
Cognitive impairment after stroke: frequency, patterns, and relationship to functional abilities
}

\author{
T K Tatemichi, D W Desmond, Y Stern, M Paik, M Sano, E Bagiella
}

\begin{abstract}
Cognitive function was examined in 227 patients three months after admission to hospital for ischaemic stroke, and in $\mathbf{2 4 0}$ stroke-free controls, using 17 scored items that assessed memory, orientation, verbal skills, visuospatial ability, abstract reasoning, and attentional skills. After adjusting for demographic factors with standardised residual scores in all subjects, the fifth percentile was used for controls as the criterion for failure on each item. The mean (SD) number of failed items was $3.4(3.6)$ for patients with stroke and $0.8(1 \cdot 3)$ for controls (p < 0.001). Cognitive impairment, defined as failure on any four or more items, occurred in $35 \cdot 2 \%$ of patients with stroke and $3.8 \%$ of controls $(p<0.001)$. Cognitive domains most likely to be defective in stroke compared with control subjects were memory, orientation, language, and attention. Among patients with stroke, cognitive impairment was most frequently associated with major cortical syndromes and with infarctions in the left anterior and posterior cerebral artery territories. Functional impairment was greater with cognitive impairment, and dependent living after discharge either at home or nursing home was more likely $(55.0 \%$ with, $v$ $32 \cdot 7 \%$ without cognitive impairment, $\mathbf{p}=0.001$ ). In a logistic model examining the risks related to dependent living after stroke, cognitive impairment was a significant independent correlate (odds ratio, $O R=2 \cdot 4$ ), after adjusting for age $(O R=5 \cdot 2,80+v 60-70$ years $)$ and physical impairment $(O R=3 \cdot 7$, Barthel index $\leqslant 40 v>40$ ). It is concluded that cognitive impairment occurs frequently after stroke, commonly involving memory, orientation, language, and attention. The presence of cognitive impairment in patients with stroke has important functional consequences, independent of the effects of physical impairment. Studies of stroke outcome and intervention should take into account both cognitive and physical impairments.
\end{abstract}

\section{(F Neurol Neurosurg Psychiatry 1994;57:202-207)}

Cerebrovascular disease is an important cause of morbidity in the elderly, resulting not only in physical disability, but also significant cognitive impairment. Most studies of stroke outcome have focused on physical consequences $^{1}$ few have examined intellectual deficits. $^{2}$ In a previous study, we found dementia in $66(26.3 \%)$ of 251 elderly patients examined with neuropsychological tests three months after hospital admission for ischaemic stroke. ${ }^{3}$ Excluding subjects with functional impairment preceding stroke onset who may have had coexisting Alzheimer's disease, the frequency of dementia in this sample was $16.3 \%$ (37 of 227 patients with stroke). Our research criteria for dementia required the presence of memory impairment combined with deficits in two additional cognitive domains. Because the frequency of dementia will depend in part on the diagnostic criteria used, ${ }^{4}$ the frequency of intellectual decline may be over-represented or underrepresented by focusing on dementia as a diagnosis.

An alternative approach to characterising the cognitive consequences of stroke would be to examine a broad range of specific neuropsychological deficits, independent of the diagnosis of dementia. If those deficits are clinically meaningful, they should be related to functional abilities, whether or not dementia is diagnosed. In this report, our aim was to determine the frequency and patterns of cognitive impairment in our cohort of patients who had no history of functional decline before stroke, compared with control subjects who lived in the community and who were free of stroke and similar in age. In addition, we related those findings to functional abilities and independent living after discharge, to determine whether our measure of cognitive impairment was relevant to adaptive functioning. Our overall goal was to provide descriptive information about general intellectual functions in a consecutive stroke sample that should have implications for studies of stroke outcome and intervention.

\section{Subjects and methods} SUBJECT SELECTION

Subjects for this study were recruited among patients admitted consecutively to ColumbiaPresbyterian Medical Center between 1 September 1988 and 31 December 1990 with acute ischaemic stroke occurring within the previous 30 days. Eligible patients were 60 years of age or older, of either sex, with the diagnosis of ischaemic stroke of any type confirmed by computed tomography of the brain (normal or focal, low density lesion) per- 
formed within one week of symptom onset. Patients were excluded when certain clinical features prevented a reliable assessment of neuropsychological function, such as a severe aphasia - that is, a score of less than three on the asphasia severity rating scale ${ }^{5}$ from the Boston diagnostic aphasia examination (BDAE); persistent impairment in consciousness from any cause; or primary language other than English or Spanish. Among the 251 patients enrolled and examined three months after the onset of stroke, we selected 227 patients for this analysis, after excluding 24 who were considered to have possible or probable Alzheimer's disease complicated by stroke, based on a history of functional impairment preceding stroke and dementia documented by neuropsychological testing.

A control group was assembled as a reference sample, consisting of 249 subjects living in the community who were over 60 years of age, and without historical or clinical evidence of stroke. Whenever they were available, we recruited as the control, the spouse of the subjects with stroke $(17 \cdot 3 \%)$. The remaining controls were obtained either by probability sampling using a roster of neighbourhood residents obtained from Medicare files and a commercial list $(53.0 \%)$, or from neighbourhood volunteers $(29 \cdot 7 \%)$ who came to our attention through advertising in the community or by word of mouth. We attempted to match controls to the subjects with stroke by age. Baseline features of the stroke patients and controls are described in a previous report. ${ }^{3}$ For the purposes of this analysis, nine controls were excluded (sample $n=240$ ): eight were judged to be demented based on clinical features and neuropsychological performance, and one had low test scores in the dementia range with a lifelong history of low intellectual attainment.

\section{NEUROPSYCHOLOGICAL AND FUNCTIONAL ASSESSMENTS}

Approximately three months after the stroke, patients were given a battery of neuropsychological tests, developed for the purpose of diagnosing dementia in a bilingual (English and Spanish), multiethnic, elderly population as part of a broader epidemiological study of dementia involving the Washington HeightsInwood community surrounding the medical centre. ${ }^{67}$ We chose an interval of three months following onset for neuropsychological testing to allow sufficient time for the acute stroke effects to subside. ${ }^{89}$ Testing was conducted in either English or Spanish, depending on the preferred language of the subject, usually the language spoken at home. Neuropsychological functions assessed by this battery included six major cognitive domains: memory, both verbal (selective reminding test ${ }^{10}$ ) and visual (recognition task on the Benton visual retention test; $\mathrm{BVRT}^{11}$ ); orientation (orientation items from the mini mental state examination ${ }^{12}$ ); language ability including naming (selected items from the Boston naming test ${ }^{13}$ ), verbal fluency (controlled word association test $^{14}$ and the category fluency subtest of the $\mathrm{BDAE}^{5}$ ), comprehension (first six items of the complex ideation subtest of the $\mathrm{BDAE}^{5}$ ) and repetition (high frequency items from the $\mathrm{BDAE}^{5}$ ); visuospatial ability (five items selected from the Rosen drawing test $^{15}$ and the matching task of the BVRT); abstract reasoning (similarities subtest of the revised Wechsler adult intelligence scale; (WAIS-R) ${ }^{16}$ and the non-verbal similarities and differences subtest of the Mattis dementia rating scale ${ }^{17}$ ); and attention (target detection tasks ${ }^{18}$ ). To examine attention, subjects were given two separate cancellation tasks requiring them to identify and mark specific targets (either geometric shapes or letter groups) as quickly as possible from an array of test stimuli, resulting in scores for errors, omissions, and total time to completion. In addition, to assess physical and non-physical functional abilities, the Blessed functional activity scale $^{19}$ (BFAS), the Barthel index (BI), ${ }^{20}$ the stroke severity scale ${ }^{21}$ and the Schwab and England Scale ${ }^{22}$ were administered. The same neuropsychological battery and functional examinations were administered to controls.

\section{CLINICAL CLASSIFICATION OF STROKE} SUBJECTS

Based on clinical findings during their stay in hospital, patients with stroke were classified by clinical syndrome and vascular territory using the methods of the Stroke Data Bank. ${ }^{21}$ Derived chiefly from neurological findings in the acute phase of the stroke, the stroke syndrome included six major types reflecting hemispheric laterality in relation to the presence or absence of language versus spatial deficits (dominant $v$ non-dominant), severity of neurological impairment (major $v$ minor), general cerebral location (hemispheric $v$ brainstem), and whether infarction was superficial or deep (lacunar $v$ all others). Thus, the six syndromes were major dominant or non-dominant hemispheral, minor dominant or non-dominant hemispheral, lacunar-deep infarction, and brainstem-cerebellar infarction. For example, a patient with a transcortical motor aphasia, ideomotor dyspraxia, and severe, right hemiparesis with crual predominance was classified as having a major, dominant hemispheral syndrome indicating widespread damage in the anterior cerebral artery. In contrast, a patient with anosognosia, left hemi-inattention and hemianopia, and left faciobrachial paresis was considered to have a major, non-dominant hemispheral syndrome in the middle cerebral artery. Vascular territory was inferred from the neurological deficit profile and the topography of relevant infarction on brain imaging obtained during their hospital stay, if positive, using the guidelines provided by Damasio. ${ }^{23}$ Territories included internal cartoid, anterior cerebral, middle cerebral, posterior cerebral and vertebrobasilar arteries. Classifications by syndrome and vascular territory were independent of information on iseuropsychological or functional testing. Based on an examination of reliability among three raters 
in a subsample of 100 subjects, inter-rater agreement on stroke features was excellent, with $\kappa=0.85$ for syndrome and $\kappa=0.93$ for territory.

\section{DATA ANALYSIS AND STATISTICS}

Mean scores of the stroke and control subjects on each of 17 scored items from the neuropsychological battery were compared using Student's two-tailed $t$ test. To summarise the attentional tests, two indices were calculated for both shape and letter target tasks: number of correct targets per second (total number of correct responses divided by total time taken to perform the test) and number of errors per correct response (ratio of errors to correct responses). The scores from the shape and letter tasks were averaged to derive the two summary indices for each patient. Although the ages (mean (SD)) of patients with stroke and controls were comparable $(70.8(7.9)$ v $70.6(6.5))$, the two groups differed in other demographic factors: sex (\% women, $52.9 \% v 65.8 \%$ ), years of education $(10.2(4.6) v 12.5(4.4))$ and race (\% non-white, $65 \cdot 2 \% v 47 \cdot 1 \%$ ). To adjust for these factors in determining the frequency of cognitive impairment, the raw test scores of each subject (total $n=467$ ) were converted to standardised residual scores, regressing demographic variables (age, sex, race, education) with each of the 17 subtest variables. The resulting standardised residual score can be considered to represent the difference between a subject's predicted and actual test score. Following the approach of Rao et al ${ }^{24}$ who studied cognitive dysfunction in multiple sclerosis, we used the fifth percentile of residual scores of the control subjects as the cut off for determining failure by patients with stroke on each item, which we used as the definition of cognitive impairment. As a summary index of cognitive impairment, the total number of failed tests for patients and con-

Table 1 Performance of controls and subjects with stroke on neuropsychological tests (values are unadjusted means (SD)), and the frequency of stroke subjects (\%) falling below the fifth percentile based on standardised residual scores

\begin{tabular}{|c|c|c|c|}
\hline Neuropsychological test item & $\begin{array}{l}\text { Controls* } \\
(n=240)\end{array}$ & $\begin{array}{l}\text { Stroket } \\
(n=227)\end{array}$ & $\begin{array}{l}\text { Frequency (\%) } \\
\text { of stroke patients below } \\
\text { fifth percentile }\end{array}$ \\
\hline \multicolumn{4}{|l|}{ Memory } \\
\hline SRT total & $42 \cdot 8(10 \cdot 6)$ & $33.1(11 \cdot 5)$ & $19 \cdot 5$ \\
\hline SRT long term & $29 \cdot 5(15 \cdot 2)$ & $18 \cdot 7(13.5)$ & $10 \cdot 2$ \\
\hline Delayed recall & $5.9(2.9)$ & $4 \cdot 2(2 \cdot 8)$ & $18 \cdot 1$ \\
\hline Delayed recognition & $11.4(1.3)$ & $10 \cdot 3(2 \cdot 2)$ & $21 \cdot 2$ \\
\hline Benton recognition & $7 \cdot 8(1 \cdot 8)$ & $6.0(2 \cdot 2)$ & $24 \cdot 6$ \\
\hline Orientation & $9 \cdot 7(0 \cdot 6)$ & $8.6(1.9)$ & $25 \cdot 8$ \\
\hline \multicolumn{4}{|l|}{ Language } \\
\hline CFL & $11.7(4.9)$ & $7 \cdot 4(4 \cdot 1)$ & $14 \cdot 4$ \\
\hline Category fluency & $17 \cdot 3(4 \cdot 9)$ & $12 \cdot 3(4 \cdot 8)$ & $32 \cdot 7$ \\
\hline Repetition & $7.8(0.5)$ & $7 \cdot 4(1 \cdot 1)$ & $15 \cdot 1$ \\
\hline Comprehension & $5.5(0.9)$ & $4 \cdot 8(1 \cdot 4)$ & $13 \cdot 3$ \\
\hline \multicolumn{4}{|l|}{ Visuospatial skills } \\
\hline Rosen construction & $3.5(1 \cdot 0)$ & $2 \cdot 5(1 \cdot 2)$ & $16 \cdot 8$ \\
\hline \multicolumn{3}{|l|}{ Abstract reasoning } & $25 \cdot 0$ \\
\hline Similarities & $10 \cdot 7(2 \cdot 9)$ & $8 \cdot 2(2 \cdot 7)$ & $16 \cdot 1$ \\
\hline Identities & $14 \cdot 8(1 \cdot 6)$ & $13 \cdot 3(2 \cdot 2)$ & $20 \cdot i$ \\
\hline \multicolumn{4}{|l|}{ Attention } \\
\hline No. correct/second & $0.17(0.08)$ & $0.27(0.09)$ & $38 \cdot 5$ \\
\hline No. errors/no. correct & $0.29(1.09)$ & $0.05(0.31)$ & $20 \cdot 2$ \\
\hline
\end{tabular}

${ }^{\star}$ Mean age $=70 \cdot 8(7.9)$ years; mean education $=10.2(4.6)$ years; $52.9 \%$ women; $65.2 \%$ nonwhite; tMean age $=70.6(6.5)$ years; mean education $=12.5(4.4)$ years; $65.8 \%$ women; $47 \cdot 1 \%$ non-white. SRT $=$ selective reminding test; CFL = verbal fluency. trols was also determined, again using the fifth percentile of performance by control subjects as the cut off for classifying a subject as cognitively impaired. In addition, a 'corrected' frequency rate of cognitive impairment in the patients with stroke was determined by computing the difference in percentage between patients with stroke and controls with cognitive impairment.

Patterns of cognitive impairment were examined using two approaches. Firstly, performance of stroke and control subjects was compared on neuropsychological test items and by cognitive domains. The 17 individual scored items of the battery were entered into a logistic regression model as independent variables to identify tests which best correlated with stroke compared with control status. The six cognitive domains as defined above were also examined in a separate logistic model. Impairment in a cognitive domain was defined as defective performance in any one or more of the items comprising that domain. The aim was to identify the neuropsychological disturbances that were independently associated with ischaemic stroke overall, compared with subjects without stroke. Secondly, within the stroke cohort, we examined the frequency of cognitive impairment by clinical syndrome and vascular territory. The aim was to identify brain topographical correlates of cognitive impairment.

To determine whether our statistical criterion defining cognitive impairment was clinically relevant, we compared the characteristics of patients with and without cognitive impairment in relation to functional impairment (BFAS, BI, stroke severity, Schwab and England scale), and whether the patient was independent after their stay in hospital (discharged home without assistance) or dependent (requiring either home attendant help or admission to a nursing home). As status at discharge is considered to be an important measure of stroke outcome, ${ }^{25}$ we also used a multiple logistic model to determine whether the presence or absence of cognitive impairment was a significant predictor of dependent living after hospital admission, adjusting for the effects of physical impairment (BI 40 or less, as an indicator of low functional ability ${ }^{25}$ ) and those sociodemographic factors (age, sex, occupation, and marital status) considered to influence discharge status. ${ }^{27} 28$

\section{Results}

FREQUENCY OF COGNITIVE IMPAIRMENT

Comparing raw neuropsychological scores, patients with stroke were impaired on all 17 scored items of the neuropsychological battery (table 1). Adjusting for demographic factors using standarised residual scores, the proportion of stroke subjects performing below the fifth percentile ranged from $10.2 \%$ to $38.5 \%$. These proportions were different from controls for each test item. The number of failed tests (mean (SD)) differed significantly between patients with stroke 


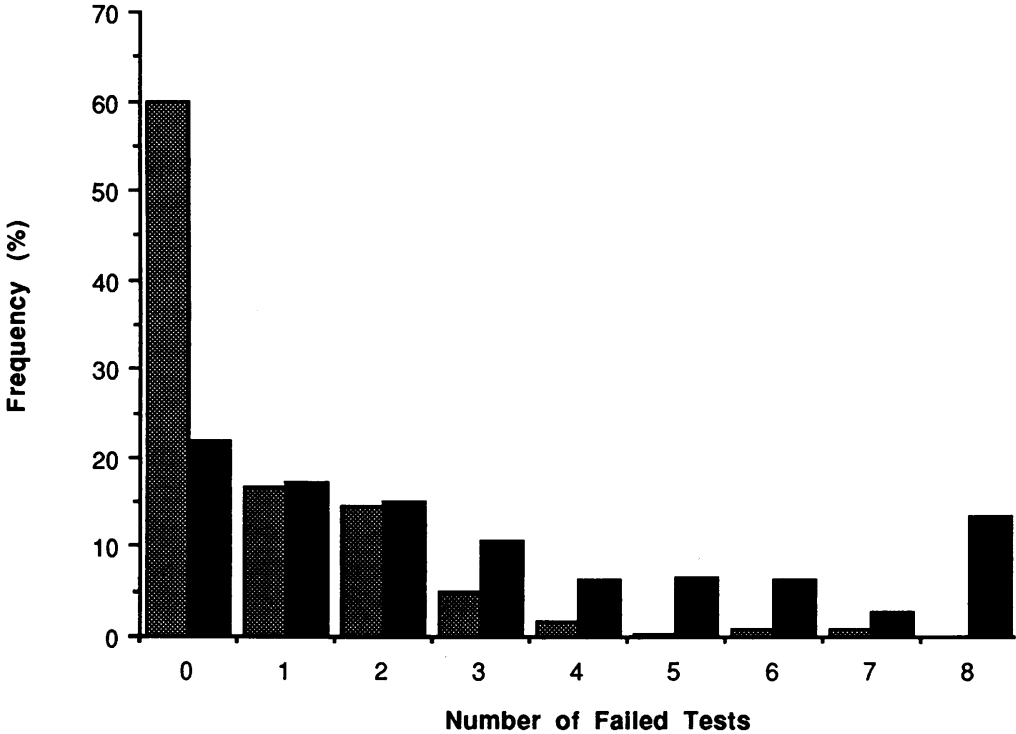

Figure Frequency distribution of the number of failed neuropsychological test items in patients with stroke (solid bars) and controls (hatched bars).

$(3 \cdot 4(3 \cdot 6))$ and controls $(0 \cdot 8(1 \cdot 3))(t(465)=$ $10 \cdot 2, \mathrm{p}<0 \cdot 001)$. The frequency distribution of the number of failed tests for the two groups is shown in the figure, indicating that $78 \%$ of patients with stroke failed one or more test items, compared with $40 \%$ of controls. Using a cut off of four or more failed tests, $35 \cdot 2 \%$ of patients compared with $3 \cdot 8 \%$ of controls were classified as cognitively impaired. As we did not require specific tests or domains for the definition of cognitive impairment, subjects with defective performance on four or more tests in a single cognitive domain-for example, language or memory-might have been classified as impaired, reflecting a circumscribed neuropsychological defect. This did not occur, however, in any patient or control classified as cognitively impaired. The true or corrected frequency of impairment associated with stroke was estimated by subtracting the "false positive" rate of the controls $(5 \cdot 0 \%)$, yielding a proportion of $30 \cdot 2 \%$.

PATTERNS OF COGNITIVE IMPAIRMENT

Using a logistic model to identify the neuropsychological correlates independently associated with stroke compared with control

Table 2 Logistic model of neuropsychological test items (model $A, 17$ total items examined) and cognitive domains (model B, 6 total domains examined) independently correlated with stroke compared with control status

\begin{tabular}{|c|c|c|c|c|}
\hline \multirow{2}{*}{$\begin{array}{l}\text { Neuropsychological } \\
\text { test item }\end{array}$} & \multicolumn{4}{|l|}{ Model $A$} \\
\hline & $\beta$ & $S E$ & $p$ & $O R$ \\
\hline Benton recognition & 0.6297 & $0 \cdot 1960$ & 0.001 & $1 \cdot 87$ \\
\hline Orier & 0.4351 & $0 \cdot 2092$ & 0.038 & 1.55 \\
\hline Category fluency & 0.7402 & 0.1905 & $<0.001$ & $2 \cdot 10$ \\
\hline Repetition & 0.4761 & 0.2061 & 0.021 & 1.61 \\
\hline \multirow[t]{2}{*}{ Attention (correct/second) } & 0.8414 & 0.1859 & $<0.001$ & $2 \cdot 32$ \\
\hline & \multicolumn{4}{|l|}{ Model B } \\
\hline Cognitive domain & $\beta$ & $S E$ & $p$ & $O R$ \\
\hline $\begin{array}{l}\text { Memory (verbal and visual) } \\
\text { Orientation } \\
\text { Language } \\
\text { Attention }\end{array}$ & $\begin{array}{l}0.4585 \\
0.4158 \\
0.4252 \\
0.7523\end{array}$ & $\begin{array}{l}0 \cdot 1270 \\
0 \cdot 2012 \\
0 \cdot 1256 \\
0 \cdot 1535\end{array}$ & $\begin{array}{r}<0.001 \\
0.039 \\
<0.001 \\
<0.001\end{array}$ & $\begin{array}{l}1 \cdot 58 \\
1.52 \\
1.53 \\
2 \cdot 12\end{array}$ \\
\hline
\end{tabular}

$\beta=$ regression coefficient; $S E=$ standard error of the mean; $\mathrm{p}=$ probability $\mathrm{OR}=$ odds ratio.
Table 3 Clinical stroke features and frequency of cognitive impairment. Percentages indicate proportions within subject groups

\begin{tabular}{lcc}
\hline & \multicolumn{2}{l}{ Cognitive impairment $n(\%)$} \\
\cline { 2 - 3 } Stroke feature & $\begin{array}{c}\text { Present } \\
(n=80)\end{array}$ & $\begin{array}{l}\text { Absent } \\
(n=147)\end{array}$ \\
\hline Stroke syndrome & & \\
Major dominant & $15(18 \cdot 8)$ & $10(6 \cdot 8)$ \\
Major non-dominant & $12(15 \cdot 0)$ & $5(3 \cdot 4)$ \\
Minor dominant & $10(12 \cdot 5)$ & $25(17 \cdot 0)$ \\
Minor non-dominant & $10(12 \cdot 5)$ & $30(20 \cdot 4)$ \\
Lacunar & $21(26 \cdot 3)$ & $38(25 \cdot 9)$ \\
Brainstem-cerebellar & $12(15 \cdot 0)$ & $39(26 \cdot 5)$ \\
Stroke territory & & \\
Left ICA & $2(2 \cdot 5)$ & $3(2 \cdot 0)$ \\
Right ICA & $1(1 \cdot 3)$ & $1(1 \cdot 4)$ \\
Left ACA & $5(6 \cdot 3)$ & $3(2 \cdot 0)$ \\
Right ACA & $1(1 \cdot 3)$ & $2(1 \cdot 4)$ \\
Left MCA & $24(30 \cdot 0)$ & $33(22 \cdot 4)$ \\
Right MCA & $25(31 \cdot 3)$ & $40(27 \cdot 2)$ \\
Left PCA & $6(7 \cdot 5)$ & $6(4 \cdot 1)$ \\
Right PCA & $4(5 \cdot 0)$ & $10(6 \cdot 8)$ \\
Vertebrobasilar & $12(15 \cdot 0)$ & $48(32 \cdot 7)$ \\
\hline Border. &
\end{tabular}

^Borderzone infarction. ICA $=$ internal cerebral artery; $\mathrm{ACA}=$ anterior cerebral artery; $\mathrm{MCA}=$ middle cerebral artery; $\mathrm{PCA}=$ posterior cerebral artery

status, impairment in the following tests was more likely to be associated with stroke (table 2): Benton recognition, orientation, category fluency, repetition, and attention (number of correct targets per second). The $\beta$ values and corresponding odds ratios may be interpreted as the risk of impairment on those test items associated with stroke compared with subjects free of stroke. When these test items were summarized into cognitive domains, the most significant areas of impairment were memory, orientation, language, and attention (table 2).

Confining the analysis to the stroke group, cognitive impairment varied by stroke syndrome $\left(\chi^{2}, \mathrm{p}<0.001\right)$. Patients with major dominant and major non-dominant syndromes were most likely to be cognitively impaired (table 3), consistent with major neurobehavioural effects from large infarctions. When cognitive impairment was examined by specific vascular territory and laterality (table 3 ), differences were less obvious, in part because of small samples in some of the subgroups. Overall, cognitive impairment appeared most frequently with infarcts in the left anterior and posterior cerebral artery territories and least frequently with infarcts in the vertebrobasilar artery territory. Examining vascular distribution independently of hemispheric side, the proportion of infarcts in the anterior cerebral artery territory was higher among those with cognitive impairment $(7 \cdot 6 \%)$ compared with those without $(3.4 \%)\left(\chi^{2}, p=0.053\right)$. Comparing left-sided, right-sided and vertebrobasilar strokes, left-sided damage was more common among those with cognitive impairment $(46.3 \%)$ compared with those without $(30.6 \%)\left(\chi^{2}, \mathrm{p}<0.001\right)$.

\section{RELATIONSHIP TO OTHER CLINICAL VARIABLES} AND FUNCTIONAL STATUS

Among patients with cognitive impairment, women predominated, despite correction for sex in the regression model (table 4). Severity of functional impairment was significantly greater with cognitive impairment, measured 
Table 4 General clinical and functional characteristics of stroke patients and frequency of cognitive impairment. Percentages indicate proportions between subject groups

\begin{tabular}{|c|c|c|c|}
\hline \multirow[b]{2}{*}{ Characteristic } & \multicolumn{3}{|c|}{ Cognitive impairment $n(\%)$} \\
\hline & $\begin{array}{l}\text { Present } \\
(n=80)\end{array}$ & $\begin{array}{l}\text { Absent } \\
(n=147)\end{array}$ & $p^{*}$ \\
\hline \multicolumn{4}{|l|}{ Demographic factors } \\
\hline Age, mean (SD) & $71 \cdot 5(7 \cdot 8)$ & $70 \cdot 5(7.9)$ & $0 \cdot 383$ \\
\hline $\begin{array}{c}\text { Sex }(\%) \\
\text { Men }\end{array}$ & $29(27 \cdot 1)$ & $78(72.9)$ & 0.015 \\
\hline Women & $51(42 \cdot 5)$ & $\begin{array}{l}78(72 \cdot 9) \\
69(57 \cdot 5)\end{array}$ & \\
\hline Race (\%) & & & 0.963 \\
\hline $\begin{array}{l}\text { Non-white } \\
\text { White }\end{array}$ & $\begin{array}{l}52(35 \cdot 1) \\
28(35 \cdot 4)\end{array}$ & $\begin{array}{l}96(64 \cdot 9) \\
51(64 \cdot 6)\end{array}$ & \\
\hline Education, mean (SD) & $10 \cdot 4(4 \cdot 2)$ & $10 \cdot 1(4 \cdot 8)$ & 0.651 \\
\hline $\begin{array}{l}\text { Screening tests of cognition and mood } \\
\text { MMSE score, mean (SD) } \\
\text { Short Blessed, mean (SD) } \\
\text { HDRS, mean (SD) }\end{array}$ & $\begin{array}{r}21 \cdot 7(5 \cdot 3) \\
10 \cdot 9(7 \cdot 1) \\
5 \cdot 5(4 \cdot 4)\end{array}$ & $\begin{array}{r}26 \cdot 4(3 \cdot 5) \\
4 \cdot 5(5 \cdot 1) \\
4 \cdot 5(4 \cdot 6)\end{array}$ & $\begin{aligned}<0.001 \\
<0.001 \\
0.096\end{aligned}$ \\
\hline $\begin{array}{l}\text { Functional and physical impairment } \\
\text { BFAS, mean (SD) } \\
\text { Barthel, mean (SD) } \\
\text { Stroke Severity, mean (SD) } \\
\text { Schwab and England, mean (SD) }\end{array}$ & $\begin{aligned} & 3 \cdot 8(3 \cdot 9) \\
& 77 \cdot 0(27 \cdot 9) \\
& 6 \cdot 0(3 \cdot 2) \\
& 66 \cdot 0(22 \cdot 4)\end{aligned}$ & $\begin{array}{c}1 \cdot 5(2 \cdot 0) \\
89 \cdot 9(17 \cdot 8) \\
4 \cdot 6(3 \cdot 2) \\
80 \cdot 3(20 \cdot 8)\end{array}$ & $\begin{array}{r}<0.001 \\
<0.001 \\
0.007 \\
<0.001\end{array}$ \\
\hline $\begin{array}{l}\text { Status after discharge (\%) } \\
\text { Independent } \\
\text { Dependent }\end{array}$ & $\begin{array}{l}36(26 \cdot 7) \\
44(47 \cdot 8)\end{array}$ & $\begin{array}{l}99(73 \cdot 3) \\
48(52 \cdot 2)\end{array}$ & 0.001 \\
\hline
\end{tabular}

Student's $t$ test for differences in means or $\chi^{2}$ for differences in proportions

MMSE = Mini mental state examination; HDRS = Hamilton depression rating scale; BFAS $=$ Blessed functional activity scale.

Table 5 Logistic model of factors independently correlated with dependent living (nursing home placement or home attendant) following discharge from the hospital

\begin{tabular}{lrrrr}
\hline & $\beta$ & $S E$ & \multicolumn{1}{c}{$p$} & \multicolumn{1}{c}{ OR } \\
\hline Age (main effect) & & & 0.001 & \\
80+ years & 1.6437 & 0.4631 & $<0.001$ & 5.17 \\
$70-79$ years & 0.5560 & 0.3162 & 0.079 & 1.74 \\
Barthel (<40 v 40+) & 1.3127 & 0.6054 & 0.030 & 3.72 \\
Cognitive impairment & 0.8766 & 0.3074 & 0.004 & 2.40 \\
Constant & -1.2218 & 0.2433 & $<0.001$ &
\end{tabular}

${ }^{\star}$ Compared with $60-69$ years. $\beta=$ regression coefficient; $S E=$ standard error of the mean; $\mathrm{p}=$ probability; $\mathrm{OR}=$ odds ratio.

by the BI, stroke severity scale, and the Schwab and England scale (table 4). Moreover, dependent living after discharge, either at home or nursing home, was more likely $(55 \cdot 0 \%$ with, $32 \cdot 7 \%$ without cognitive impairment, $p=0.001$ ). In a logistic model examining the risks related to dependent living after stroke (table 5), cognitive impairment was a significant predictor $(O R=2 \cdot 4$; $95 \%$ confidence interval, $1 \cdot 3$ to $4 \cdot 4)$, after adjusting for age $(\mathrm{OR}=5 \cdot 2,80+v$ 60-70 years) and physical impairment $(O R=3 \cdot 7$, BI $\leqslant 40 v>40$ ). Marital status was borderline in significance, while sex and occupation were not significantly related.

\section{Discussion}

In this report, our intent was not to describe those circumscribed neurobehavioural syndromes that are well known after focal brain infarction ${ }^{29}$; nor did we directly examine dementia, which we have previously described in this sample, defined by the presence of specific cognitive deficits in combination using modified DSM-III-R criteria. $^{3}$ Rather, our aim was to focus on cognitive impairment as a general indicator of intellectual decline following ischaemic stroke, ${ }^{30}$ which we defined as failure on any four or more neuropsychological test items using a statistical criterion based on normative data from a stroke-free sample.
Our approach raises several important methodological and conceptual issues in neuropsychological studies of patients with cerebrovascular disease. A fundamental problem, common to all studies using psychometric tests, is the definition of normality compared with abnormality or impairment, a discrimination that depends in part on the reference group or standard selected. Four approaches have been typically used, including comparison with: premorbid ability; a non-clinical sample without the disorder or exposure; a clinical sample with the disorder or exposure; or predetermined cut off criteria based on externally derived standards. The first approach provides the most clinically meaningful information for the affected individual, even though impractical or difficult to estimate with accuracy; the last approach is potentially the most arbitrary.

We used the second approach, a commonly accepted method to define abnormality which is perhaps least arbitrary, but susceptible to biases related to subject variables (age, education, sex, and race) known to affect psychometric test performance independent of disease state. ${ }^{31}{ }^{32}$ After adjusting for these factors, however, the frequency of cognitive impairment in our elderly patients was high, evident in approximately a third of patients examined three months after ischaemic stroke. A similar frequency of impairment in orientation $(27 \%$ for "confusion or unassessable") and a figure copying task (26\% for "failed or unassessable") was observed in a study of 470 patients examined six months after stroke. ${ }^{2}$ In another related study, immediate logical memory (evaluated by recall of a story) was defective in $29 \%$ of 138 patients examined three months after stroke. ${ }^{33}$

A further methodological and conceptual issue pertains to the relationship of our definition of cognitive impairment to the diagnosis of dementia. In our analysis of deficit patterns, we found that cognitive impairment varied by stroke syndrome (most frequent with large, dominant and non-dominant infarcts) and vascular territory (most frequent with dominant anterior and posterior cerebral artery territory infarcts, findings that were similar to the clinical correlations when dementia was used as the outcome. ${ }^{34}$ Moreover, when comparing patients with stroke with those without clinically evident cerebrovascular disease, the cognitive domains most likely to be defective were memory, orientation, language, and attentional functions. Defective memory and orientation are considered to be the clinical hallmarks of dementia, and appear to be the best psychometric discriminators of normal ageing from dementia. ${ }^{35}$ These findings together suggest that our definition of cognitive impairment identifies patients who are less severely affected within the spectrum of intellectual decline, with dementia representing the most extreme state. A further implication arising from the identification of specific cognitive domains impaired with focal stroke 
is their potential relevance in screening for cognitive impairment or dementia among patients with stroke. For example, the mini mental state examination, which we have found to have acceptable sensitivity and specificity as a dementia screen in cerebrovascular disease, ${ }^{36}$ contains test items that assess those four domains.

Although we have circumvented the potential problems of definitions posed by using dementia as a diagnosis, ${ }^{4}$ our use of a statistical criterion raises the question of clinical relevance. Based on our analysis of discharge status as an outcome, the presence of cognitive impairment significantly correlated with dependent living after admission to hospital (whether requiring nursing home or home attendant care), even after adjusting for the effects of age and physical impairment. Although this finding is neither novel nor unexpected, it serves as an indirect validation of our approach and, more importantly, emphasises the potential value of neuropsychological assessment of patients with stroke. It is further consistent with our previous finding that poor performance on the mini mental state examination in the first week after acute ischaemic stroke is among the most important predictors of disability three months later. ${ }^{3}$ Yet mental function tests have largely been ignored or limited in both observational outcome studies ${ }^{21}$ and interventional clinical trials aimed at minimising neurological disability from ischaemic stroke. ${ }^{37} \mathrm{We}$ therefore conclude that cognitive impairment is not only frequent with stroke, but also significantly affects functional adaptation after the acute phase. Efforts to modify the course of acute stroke should also take into account "chronic brain failure" 38 as an outcome.

The authors are indebeted to Ms Georgina Ferrer, Leslie Hanzawa, RN, and Beth Rosenstein for their assistance in the clinical evaluation of our patients, and to Professors Richard Mayeux and J P Mohr for their critical review of the manuscript.

This work was supported in part by Grants NS26179 and AG07232 from the National Institutes of Health, USA

1 Gresham GE, Phillips TE, Wolf PA, McNamara PM, Kannel WB, Dawber TR. Epidemiological profile of long-term stroke disability: the Framingham study. Arch Phys Med Rehabil 1979;60:487-91.

2 Wade DT, Skilbeck C, Hewer RL. Selected cognitive losses after stroke. Int Disabil Stud 1989;11:34-9.

3 Tatemichi TK, Desmond DW, Mayeux R, et al. Dementia after stroke: baseline frequency, risks, and clinical features in a hospitalized cohort. Neurology clinical features

4 Tatemichi TK, Desmond DW, Stern Y, Sano M, Mayeux $\mathrm{R}$, Andrews H. Prevalence of dementia depends on
diagnostic criteria (abstract). Neurology 1992; diagnostic crite

5 Goodglass $\mathrm{H}$, Kaplan $\mathrm{E}$. The assessment of aphasia and related disorders, 2nd edn. Philadelphia: Lea and Febiger, 1983

6 Stern Y, Andrews H, Pittman J, et al. Diagnosis of dementia in a heterogeneous population: Part I. Development of a neuropsychological paradigm and quantified correction for education. Arch Neurol 1992;49:453-60.

7 Pittman J, Andrews H, Tatemichi T, et al. Diagnosis of dementia in a heterogenous population: Part II.
Comparison on a paradigm-based diagnosis and physician's diagnosis. Arch Neurol 1992;49:461-7.

8 Skilbeck CE, Wade DT, Hewer RL, Wood VA. Recovery after stroke. $\mathcal{F}$ Neurol Neurosurg Psychiatry 1983;46:5-8.

after stroke. F Neurol Neurosurg Psychiatry 1983;46:5-8.
9 Wade DT, Wood VA, Hewer RL. Recovery after strokethe first three months. $\mathcal{F}$ Neurol Neurosurg Psychiatry 1985;48:7-13.

10 Bushke H, Fuld PA. Evaluating storage, retention, and retrieval in disordered memory and learning. Neurology 1974;24:1019-25.

11 Benton AL. The visual retention test. New York: The Psychological Corporation, 1955

12 Folstein MF, Folstein SE, McHugh PR. Mini-mental state: A practical method for grading the cognitive state of patients for the clinician. F Psychiatr Res 1975;12: $189-98$.

13 Kaplan E, Goodglass H, Weintraub S. Boston naming test. Philadelphia: Lea and Febiger, 1983.

14 Benton A. FAS test. In: Spreen O, Benton A, eds. Neurosensory center comprehensive examination for aphasia. Neurosensory center comprehensive examination
Victoria, BC: University of Victoria, 1967.

15 Rosen W. The Rosen drawing test. New York: Veterans Administration Medical Center, 1983.

16 Wechsler D. Wechsler adult intelligence scale-revised. New York: The Psychological Corporation, 1981.

7 Mattis S. Mental status examination for organic mental syndrome in the elderly patient. In: Bellak L, Karasu TB, eds. Geriatric psychiatry. New York: Grune and Stratton, 1976

18 Sano M, Rosen W, Mayeux R. Attention deficits in Alzheimer's disease. Presented at the 92nd annual meeting of the American Psychological Association, Toronto, Canada, August, 1984.

19 Blessed G, Tomlinson BE, Roth $M$. The association between quantitative measures of dementia and of senile between quantitative measures of dementia and of senile change in the cerebral grey mat

20 Mahoney FI, Barthel DW. Functional evaluation: Barthel index. Md State Med 7 1965;14:61-5.

21 Foulkes MA, Wolf PA, Price TR, Mohr JP, Hier DB. The Stroke Data Bank: design, methods, and baseline characteristics. Stroke 1988;19:547-54.

22 Schwab R, England A. Projection technique for evaluating surgery in Parkinson's disease. In: Gillingham F, Donaldson I, eds. Third symposium on Parkinson's disease. London: $\mathrm{E}$ and S Livingstone, 1969.

23 Damasio H. A computed tomographic guide to the identification of cerebral vascular territories. Arch Neurol 1983;40:138-42.

24 Rao SM, Leo GJ, Bernardin L, Unverzagt F. Cognitive dysfunction in multiple sclerosis. I. Frequency, patterns, dysfunction in multiple sclerosis. I. Frequen

25 Granger CV, Sherwood CC, Greer DS. Functional status measures in a comprehensive stroke care program. Arch measures in a comprehensive strok
Phys Med Rehabil 1977;58:555-61.

26 Wade DT, Skilbeck CE, Hewer RL. Predicting Barthel ADL score at 6 months after an acute stroke. Arch Phys Med Rehabil 1983;64:24-8.

27 Kelly-Hayes M, Wolf PA, Kannel WB, Sytkowski P, D'Agostino RB, Gresham GE. Factors influencing survival and need for institutionalization following stroke: The Framingham Study. Arch Phys Med Rehabil 1988;69:415-8.

28 DeJong G, Branch LG. Predicting the stroke patient's ability to live independently. Stroke 1982;13:648-55.

29 Bornstein RA, Brown G, eds. Neurobehavioral aspects of cerebrovascular disease. New York: Oxford, 1991.

30 Hom J, Reitan RM. Generalized cognitive function after stroke. f Clin Exp Neuropsychol 1990;12:644-54.

31 Adams RL, Boake C, Crain C. Bias in neuropsychological test classification related to education, age, ethnicity. f Consult Clin Psychol 1982;50:143-5.

32 Heaton RK, Grant I, Matthews CG. Differences in neuropsychological test performance associated with age, education, and sex. In: Grant I, Adams KM, eds. Neuropsychological assessment of neuropsychiatric disorders: clinical methods and empirical findings. New York: Oxford, 1986:100-120.

33 Wade DT, Parker V, Hewer RL. Memory disturbance after stroke: frequency and associated losses. Int Rehabil Med 1986;8:60-4.

34 Tatemichi TK, Desmond DW, Paik M, Mayeux R, Mohr JP. Clinical correlates of dementia following stroke JP. Clinical correlates of dementia

35 Christensen H, Dadzi-Pavlovic D, Jacomb P. The psychometric differentiation of dementia from normal aging. metric differentiation of dementia from
7 Consult Clin Psychol 1991;3:147-55.

36 Tatemichi TK, Desmond DW, Paik M, et al. The 'MiniMental State' Examination as a screen for dementia following stroke (abstract). I Clin Exp Neuropsychol 1991;13:419.

37 Brott T. Utility of the NIH Stroke Scale. Cerebrovasc Dis 1992;2:241-2.

38 Tatemichi TK. How acute brain failure becomes chronic A view of the mechanisms of dementia related to stroke. Neurology 1990;40:1652-9. 